\title{
Características de carcaça e dos componentes não-carcaça de cabritos Moxotó e Canindé submetidos a dois níveis de alimentação ${ }^{1}$
}

\author{
Carla Wanderley Mattos ${ }^{2}$, Francisco Fernando Ramos de Carvalho ${ }^{3,4}$, Wilson Moreira Dutra \\ Júnior $^{3}$, Antonia Sherlânea Chaves Véras ${ }^{3,4}$, Ângela Maria Vieira Batista ${ }^{3,4}$, Kaliandra Souza \\ Alves $^{5}$, Valéria Louro Ribeiro ${ }^{2}$, Maria Josilaine Matos dos Santos Silva ${ }^{2}$, Geovergue \\ Rodrigues de Medeiros ${ }^{5}$, Rodrigo Mascarenhas Jordão de Vasconcelos $^{6}$, Alessandra Oliveira \\ de Araújo7, Suellen Brandão de Miranda ${ }^{7}$
}

\footnotetext{
1 Parte da dissertação de Mestrado da primeira autora.

2 Pós-Graduação em Zootecnia da UFRPE.

${ }^{3}$ Departamento de Zootecnia.

${ }^{4}$ Bolsista de Produtividade em Pesquisa do CNPq.

5 Programa de Doutorado Integrado em Zootecnia da UFRPE.

${ }^{6}$ Graduação em Zootecnia - UFRPE. Bolsista PIBIC/UFRPE/CNPq

7 Graduação em Zootecnia - UFRPE. Bolsista do PET.
}

RESUMO - Foram utilizados 22 cabritos não-castrados (10 Moxotó e 12 Canindé com peso médio inicial de $15 \mathrm{~kg}$ ) confinados em baias individuais. Os animais foram distribuídos em um delineamento inteiramente casualizado, em arranjo fatorial 2 × 2 (duas raças e dois níveis de alimentação: $\mathrm{AV}=$ à vontade e $\mathrm{AR}=30 \%$ de restrição). Foram avaliados os rendimentos de carcaça quente (RCQ), verdadeiro (RV) e comercial (RC), os cortes da carcaça e o rendimento dos componentes não-carcaça em relação ao peso do corpo vazio (PCV). Cabritos alimentados à vontade apresentaram maiores RCQ e RC e porções comestíveis da carcaça. O rendimento verdadeiro não foi influenciado pelo maior nível de alimentação. Após o abate e resfriamento da carcaça, foram feitos os seguintes cortes: pescoço, paleta, costelas $\left(1^{\mathrm{a}}-5^{\mathrm{a}}\right)$, costelas $\left(6^{\mathrm{a}}-13^{\mathrm{a}}\right)$, lombo, perna e baixo. Apesar do maior peso $(\mathrm{kg})$ dos cortes dos animais alimentados AV, não foi observada diferença entre seus rendimentos em relação ao peso da carcaça fria. O rendimento da perna foi afetado pelo nível de alimentação, sendo menor para os grupos com nível de alimentação AV. Os rendimentos do fígado, da cabeça e do trato gastrintestinal foram influenciados pelo nível de alimentação. A raça não foi determinante de diferenças nas características de carcaça e dos componentes não-carcaça, assim como no rendimento dos cortes quando o peso e o tamanho à maturidade foram semelhantes. A restrição alimentar afetou o desenvolvimento e a deposição de tecidos nos animais, resultando em menores rendimentos e quilogramas de carcaça fria a ser comercializada.

Palavras-chave: caprinos, carne, cortes comerciais, rendimento, vísceras

\section{Characteristics of carcass and non-carcass components of Moxotó and Canindé male kids under two feeding levels}

\footnotetext{
ABSTRACT- Twenty-two non-castrated male kids (10 Moxotó and 12 Canindé) averaging $15 \mathrm{~kg}$ of initial body weight and housed in individual pens were used in this trial. Animals were assigned to a completely randomized design in a $2 \times 2$ factorial arrangement of treatments [two breeds and two feeding levels: ad libitum(AL) or 30\% of feed restriction (FR). Animals fed AL had greater yields of hot carcass, cold carcass, and carcass edible parts compared to those fed FR. It was not observed a significant feeding level effect on true carcass yield. After slaughter and cooling of the carcasses the following cuts were done: neck, shoulder clod, ribs $\left(1^{\text {st }}-5^{\text {th }}\right.$ and $\left.6^{\text {th }}-13^{\text {th }}\right)$, loin, leg and breast. Although animals fed AL had greater body weights than FR kids, no significant differences were found between treatments for the different carcass cuts when expressed as percentage of cold carcass weight. Hind leg yield was affected by feeding level being lower in animals fed AL. Yields of liver, head, and gut, as percentage of empty body weight, were also affected by feeding level. Feed restriction had a negative effect on development and tissue deposition leading to lower cold carcass yield and weight. It can be concluded that when size and mature weight were similar, breed was not responsible for the differences on carcass characteristics, non-carcass components, and commercial cuts.
}

Key Words: commercial cuts, goats, meat, viscera, yield 


\section{Introdução}

Nos últimos dez anos, tem-se observado aumento na demanda da carne caprina em decorrência de suas propriedades dietéticas. Os caprinos caracterizam-se por apresentar carcaças com pouca gordura de cobertura e carne com teores de gordura inferiores aos encontrados em bovinos e ovinos (Warmington \& Kirton, 1990).

A sazonalidade do período chuvoso e as secas periódicas no Nordeste ocasionam redução na oferta de alimentos, com efeitos negativos sobre a produção animal. A produção de carne depende do genótipo e do ambiente em que o animal é criado (Barros et al., 1999). O genótipo consiste em um importante componente do sistema de produção em regime intensivo, pois influencia a velocidade do ganho de peso, a precocidade e a conversão alimentar, as quais se encontram diretamente relacionadas aos custos de alimentação e à qualidade da carcaça.

A alimentação é o principal componente dos custos de produção. Na caprinocultura, técnicos e pesquisadores, ao longo dos anos, têm procurado alternativas para redução de custos, como a substituição de concentrado por volumoso (Moron-Fuenmayor \& Clavero, 1999), níveis crescentes de suplementação protéica (Mtenga \& Kitaly, 1990; Atti et al., 2004), restrição alimentar temporária (Sahlu et al., 1999), utilização de dieta única e níveis crescentes de restrição alimentar (Yáñez, 2002; Pereira Filho, 2003). Yáñez (2002), trabalhando com níveis de restrição $(0,30$ e $60 \%)$ em cabritos Saanen abatidos aos $35 \mathrm{~kg}$, verificou que os rendimentos verdadeiro e comercial foram semelhantes nos níveis 0 e $30 \%$ e concluiu que a restrição alimentar (até 30\%) pode ser utilizada como ferramenta para reduzir o custo de produção, pois não afetou o rendimento da carcaça. Pereira Filho (2003), trabalhando com os mesmos níveis de restrição em cabritos F1 Boer x Saanen abatidos aos $25 \mathrm{~kg}$, observou que os rendimentos verdadeiro, comercial e de carcaça quente não foram influenciados pela redução na oferta de alimentos e concluiu que a restrição no nível de até $30 \%$ pode consistir em boa alternativa para o produtor quando o objetivo for a obtenção de carcaças de boa qualidade, com bom rendimento, elevada proporção de músculo e baixo teor de gordura.

No Brasil, a comercialização de caprinos é feita por meio de observações no animal, sendo o peso corporal o principal parâmetro adotado e a carcaça, seu componente de maior valor comercial (Mendonça et al., 2003). O estudo da carcaça visa à avaliação de parâmetros subjetivos e objetivos, relacionados a aspectos qualitativos e quantitativos (Garcia et al., 2003). Na Região Nordeste, o abate de caprinos é feito tradicionalmente quando os animais apresentam 25 a $30 \mathrm{~kg}$ de peso corporal, resultando em carcaças com média de 12 a $13 \mathrm{~kg}$, procedentes, contudo, de animais com mais de um ano de idade.

A valorização de uma carcaça depende, entre outros fatores, da relação peso corporal:idade de abate, cujo objetivoé a obtenção de pesos maiores em idades menores, de forma a atender às exigências do mercado consumidor. De acordo com Colomer-Rocher (1987), a produção eficiente de carne caprina deve se basear no sistema em que os animais, em curto espaço de tempo e a custos reduzidos, produzam carcaças que possam ser comercializadas a preços elevados.

A espécie caprina apresenta rendimento de carcaça quente de 39 a 54\% (Bellaver et al., 1983; El Khidir et al., 1998; Anous \& Mourad, 2001), rendimento comercial ou de carcaça fria de 38 a 51\% (El Khidir et al., 1998; Bueno et al., 1999; Cunha et al., 2000; Yamamoto et al., 2000; Zundt et al., 2001; Dhanda et al., 2003) e rendimento verdadeiro ou biológico de 51 a 57\% (Yáñez, 2002; Dhanda et al., 2003; Sen et al., 2004). Essas variações são influenciadas, em geral, por fatores como raça, idade, peso ao abate, sexo e sistema de criação, mas as diferentes metodologias empregadas na determinação destes parâmetros dificultam a comparação dos resultados obtidos nas diferentes partes do mundo (Colomer-Rocher et al., 1988; Yáñez, 2002).

Bellaver et al. (1983), avaliando características de carcaça de quatro raças caprinas do Nordeste brasileiro (Moxotó, Canindé, Marota e Repartida), encontraram rendimentos de carcaça quente e fria, em relação ao peso corporal ao abate, de 39,5 e 40,6\%, respectivamente. Figueiredo et al. e Padilha, citados por Costa et al. (1990), estudando características de caprinos nativos criados em sistema tradicional de manejo no Nordeste do Brasil, verificaram rendimento de carcaça em torno de 34,5 e 39,4\%, respectivamente.

As carcaças são comercializadas inteiras ou na forma de cortes. Os cortes cárneos variam de região para região e, principalmente, entre países, como resultado do hábito de seus consumidores (Silva Sobrinho \& Gonzaga Neto, 2004). Segundo Yáñez (2002), no Brasil, não existe padronização na comercialização de carcaças nem de seus cortes.

No Nordeste do Brasil, é comum a utilização de órgãos e vísceras na culinária regional em pratos tradicionais, como sarapatel e buchada. A importância dos componentes não-carcaça não está relacionada apenas ao rendimento, mas também ao alimento que poderia consistir em alternativa alimentar de populações menos favorecidas, as quais necessitam, invariavelmente, de proteína de origem animal. 
A obtenção de informações sobre os componentes nãocarcaça pode agregar maior valor econômico ao animal e, conseqüentemente, motivar os produtores a maiores cuidados com o rebanho (Costa et al., 1999; Rosa et al., 2002), possibilitando que o animal expresse seu potencial genético (Costa et at., 1999).

O objetivo neste trabalho foi avaliar o efeito da raça e do nível de alimentação sobre as características de carcaça e o rendimento dos cortes comerciais e dos componentes não-carcaça em cabritos Moxotó e Canindé.

\section{Material e Métodos}

O trabalho foi conduzido no Setor de CaprinoOvinocultura da Universidade Federal Rural de Pernambuco (UFRPE), localizada na Região Metropolitana do Recife $\mathrm{PE}$, latitude $8^{\circ} 04^{\prime} 03^{\prime \prime} \mathrm{S}$, longitude $34^{\circ} 55^{\prime} 00^{\prime \prime} \mathrm{O}$ e altitude de 4 m (Ache Tudo e Região, 2004).

O clima local, segundo a classificação de Köppen, é o tropical quente úmido, do tipo Aws, com duas estações bem definidas (seca e chuvosa). A temperatura do ar varia de 18 a $34^{\circ} \mathrm{C}$, com média de $26^{\circ} \mathrm{C}$ (Instituto do Milênio, 2005).

Vinte e dois cabritos machos não-castrados, 12 Canindé e dez Moxotó (idade média inicial de quatro meses e peso médio de $15 \mathrm{~kg}$ ), foram identificados, pesados e tratados contra ecto e endoparasitas. Em seguida, foram alojados em baias individuais medindo 1,00 x 2,80 m, em alvenaria e chão batido, providas de comedouro e bebedouro, onde foram submetidos a um período de adaptação no qual receberam alimentação à vontade, calculada conforme a quantidade de sobras referente ao dia anterior, mantida em torno de $20 \%$.

Os tratamentos foram definidos em função do nível de ingestão da dieta experimental, sendo pré-estabelecidos da seguinte forma: $\mathrm{AV}=$ alimentação à vontade e $\mathrm{AR}=30 \%$ de restrição. À medida que os animais atingiram $15 \mathrm{~kg}$ de peso corporal, formaram-se grupos homogêneos de dois animais, um para cada dieta, dando-se início à fase experimental. Nesta fase, o ajuste de $20 \%$ das sobras foi feito apenas para os animais com alimentação à vontade.

Os grupos foram abatidos à medida que os animais com alimentação AV atingiram o peso corporal ao abate (PCA), em torno de $25 \mathrm{~kg}$.

A dieta experimental (Tabela 1), com $40 \%$ de volumoso e $60 \%$ de concentrado, foi composta de feno de tifton (Cynodon dactylon, (L.) Pers) picado em máquina forrageira com peneira de $4 \mathrm{~mm}$, grão de milho moído, farelo de soja, farelo de trigo, óleo vegetal, calcário calcítico e mistura mineral.

A ração foi fornecida às 8 e $15 \mathrm{~h}$, em forma de ração completa. $\mathrm{O}$ fornecimento na fase pré-experimental foi de
Tabela 1 - Participação dos ingredientes (\%) e composição bromatológica da ração (\%MS)

Table 1 - Ingredient and chemical compositions of the experimental diets (\%DM)

\begin{tabular}{lc}
\hline $\begin{array}{l}\text { Ingrediente } \\
\text { Ingredient }\end{array}$ & $\begin{array}{c}\text { \% da MS } \\
\% \text { of } D M\end{array}$ \\
\hline Feno de tifton (Cynodon dactylon (L.) Pers) & 40,0 \\
Tifton hay (Cynodon dactylon (L.) Pers) & \\
Milho moído (Ground corn) & 22,1 \\
Farelo de soja (Soybean meal) & 18,4 \\
Farelo de trigo (Wheat bran) & 14,9 \\
Óleo vegetal (Vegetable oil) & 2,0 \\
Cálcario calcítico(Limestone) & 1,6 \\
Sal mineral commercial (Mineral salt) & 1,0
\end{tabular}

Composição química

Chemical composition

\begin{tabular}{|c|c|}
\hline MS $(D M), \%$ & 94,0 \\
\hline $\mathrm{PB}(C P), \% \mathrm{MS}$ & 19,5 \\
\hline $\mathrm{EE}, \% \mathrm{MS}$ & 4,8 \\
\hline $\mathrm{FDN}(N D F), \% \mathrm{MS}$ & 46,2 \\
\hline FDA $(A D F), \% \mathrm{MS}$ & 22,1 \\
\hline $\mathrm{MO}(O M), \% \mathrm{MS}$ & 92,4 \\
\hline $\mathrm{CT}(T C), \% \mathrm{MS}$ & 68,0 \\
\hline $\mathrm{CNF}(N F C), \% \mathrm{MS}$ & 24,9 \\
\hline MM (ash), \% MS & 7,6 \\
\hline EM $(M E)$, Mcal de EM/kg de $\mathrm{MS}^{2}$ & 2,6 \\
\hline $\mathrm{Ca}(\% \mathrm{MS})^{3}$ & 0,9 \\
\hline $\mathrm{P}(\% \mathrm{MS})^{3}$ & 0,4 \\
\hline \multicolumn{2}{|c|}{$\begin{array}{l}{ }^{1} \text { Níveis de garantia/kg (Guaranty levels } / \mathrm{kg} \text { ): vit. } \mathrm{A}=135.000 \mathrm{UI} ; \text { vit. } \mathrm{D}_{3}= \\
68.000 \mathrm{Ul} \text {; vit. } \mathrm{E}=450 \mathrm{mg} ; \mathrm{Ca}=240 \mathrm{~g} ; \mathrm{P}=71 \mathrm{~g} ; \mathrm{K}=28,2 \mathrm{~g} ; \mathrm{S}=20 \mathrm{~g} ; \\
\mathrm{Mg}=20 \mathrm{~g} ; \mathrm{Co}=30 \mathrm{mg} ; \mathrm{Cu}=400 \mathrm{mg} ; \mathrm{Cr}=10 \mathrm{mg} ; \mathrm{Fe}=2.500 \mathrm{mg} ; \\
\mathrm{I}=40 \mathrm{mg} ; \mathrm{Mn}=1.350 \mathrm{mg} ; \mathrm{Se}=15 \mathrm{mg} ; \mathrm{Zn}=1.700 \mathrm{mg} ; \mathrm{F} \text { (máx.) }=710 \\
\text { mg; Solubilidade do fósforo em ac. cítrico a } 2 \% \text { (mín) }=95 \% \text {. } \\
2 \text { Obtida a partir da estimativa do NDT (NRC, } 2001 \text { ) e pelas relações: } 1 \mathrm{~kg} \\
\text { de NDT }=4,409 \mathrm{Mcal} \mathrm{ED} \text { e EM }=81,7 \% \mathrm{ED} \text { (Obtained fromestimated NDT }[\mathrm{NRC} \text {, } \\
\text { 2001] and by assuming: } 1 \mathrm{~kg} T \mathrm{TDN}=4.409 \mathrm{Mcal} D E \text { and } \mathrm{ME}=81.7 \% \text { DE). } \\
{ }^{3} \text { Estimado segundo Valadares Filho et al. (2002) (Estimated according to } \\
\text { Valadares Filho et al., 2002). }\end{array}$} \\
\hline
\end{tabular}

4\% do peso corporal, com base na MS, ajustado diariamente de forma que os animais pudessem desfrutar do consumo voluntário. Na fase experimental, o fornecimento para os animais com AR foi feito com base no consumo de MS efetuado pelos animais com AV, ou seja, $70 \%$ do consumido pelo AV.

Ao atingir o peso de abate, os animais foram pesados para determinação do peso corporal final (PC) e, depois, foram submetidos a jejum de sólidos (17 horas). Após o jejum, foram novamente pesados para obtenção do peso corporal ao abate (PCA). A perda de peso decorrente do jejum foi obtida pela expressão:

$$
\mathrm{PJ}=\mathrm{PC}-\mathrm{PCA}
$$

$\mathrm{O}$ abate foi realizado por atordoamento, seguido de sangria por quatro minutos, com corte da carótida e jugular. Feita a esfola e evisceração, foram retiradas a cabeça (secção na articulação atlanto-occipital) e as patas (secção nas articulações carpo e tarsometatarsianas) para registro do peso da carcaça quente, incluindo rins e gordura pélvicarenal (PCQrg). Foi obtido ainda o peso dos componentes 
não-carcaça (sangue, cabeça, patas, pele, língua, coração, pericárdio, pulmões, traquéia, esôfago, baço, fígado/ vesícula, pâncreas, diafragma, gordura total não-carcaça, rúmen/retículo, omaso, abomaso, intestino delgado, intestino grosso, rins, bexiga, pênis e testículos) para determinação de seu rendimento em relação ao peso do corpo vazio (PCV). O peso da cabeça e das patas foi registrado com a pele que as recobriam. A gordura total não-carcaça compreendeu as gorduras omental, mesentérica, pélvicarenal e interna [(compreendendo a gordura envolta do pericárdio, bexiga, testículos e aquelas mais aderidas ao trato gastrintestinal (TGI)].

O TGI (rúmen/retículo, omaso, abomaso, intestinos delgado e grosso) foi pesado cheio e, em seguida, esvaziado, lavado e novamente pesado para determinação do PCV, obtido pela diferença entre o PCA e o conteúdo do trato gastrintestinal (CTGI), para estimativa do rendimento verdadeiro da carcaça $(\mathrm{RV}(\%)=$ PCQ / PCV x 100).

Posteriormente, as carcaças foram mantidas em câmara por 24 horas a $2^{\circ} \mathrm{C}$, com as articulações tarsometatarsianas distanciadas em $14 \mathrm{~cm}$, por meio de ganchos apropriados. Ao final deste período, foi registrado o peso da carcaça fria, incluindo rins e gordura pélvica-renal (PCFrg), sendo calculado o índice de quebra por resfriamento $(\mathrm{IQ}=(\mathrm{PCQ}$ rg PCFrg)/PCQrg) x 100. Obtidos os pesos dos rins e da gordura pélvica-renal, seus valores foram subtraídos para determinação dos pesos da carcaça quente (PCQ) e fria $(\mathrm{PCF})$ e dos rendimentos comercial $(\mathrm{RC}(\%)=\mathrm{PCF} / \mathrm{PCA} \mathrm{x}$ $100)$ e de carcaça quente (RCQ $(\%)=$ PCQ / PCA x 100).

Após a retirada da cauda, cada carcaça foi dividida longitudinalmente e as meia-carcaças foram seccionadas em sete regiões anatômicas, segundo metodologia adaptada de Colomer-Rocher (1988), Yáñez (2002) e Garcia et al. (2003): pescoço (região das sete vértebras cervicais), paleta (obtida pela desarticulação da escápula), costelas verdadeiras (possuem como base óssea as cinco vértebras torácicas), costelas falsas (região entre a 6 e $13 \underline{a}$ vértebras torácicas), lombo (compreendendo as seis vértebras lombares), perna (obtido pela secção entre a última vértebra lombar e a primeira sacra) e baixo (obtido traçando um corte inicial a partir da interseção da parte dorsal do músculo Rectus abdominis e o limite ventral da porção carnosa do músculo Obliquos internus, no plano de articulação entre a $5^{\mathrm{a}}$ e a $6^{\mathrm{a}}$ vértebra lombar, até a extremidade cranial ou manúbrio do esterno). O peso individual de cada corte, composto pelos cortes efetuados nas meia-carcaças esquerda e direita, foi registrado para cálculo de sua proporção em relação à soma das duas meia-carcaças, obtendo-se o rendimento comercial dos cortes da carcaça.
O delineamento utilizado foi o inteiramente casualizado (DIC) em arranjo fatorial 2 × 2 (duas raças e dois níveis de alimentação), com seis repetições para a raça Canindé e cinco para a Moxotó, em razão da morte de dois animais. Foi feita análise de variância e, para comparação de médias, utilizou-se o teste $\mathrm{F}(\mathrm{P}=0,001 ; 0,01$ e 0,05$)$. Todos os dados foram analisados pelo programa SAEG - Sistemas de Análises Estatísticas e Genéticas (UFV, 1998).

\section{Resultados e Discussão}

Não foi observada influência da interação raça $\times$ nível de alimentação sobre as variáveis analisadas neste estudo. $\mathrm{O}$ consumo de alimentos dos animais com AR representou $62,8 \%$ do consumido pelos AV, ou seja, verificou-se restrição real de $37,2 \%$ em relação aos animais com AV.

A raça não influenciou nenhuma das variáveis relacionadas aos pesos e rendimentos da carcaça (Tabela 2). Cunha et al. (2000) também não encontraram diferenças significativas entre cabritos Saanen e mestiços Boer $\mathrm{x}$ Saanen para peso ao abate, rendimento de carcaça quente e rendimento comercial, tendo em vista o tamanho e o peso adulto à maturidade de animais da raça Saanen. Segundo McClelland et al. (1976), grande parte das diferenças na composição corporal entre grupos raciais ao mesmo peso simplesmente reflete diferenças de maturidade relativa entre raças, justificando os resultados obtidos, uma vez que as raças Moxotó e Canindé, segundo a Associação Brasileira dos Criadores de Caprinos (ABCC, 2000), apresentam tamanho e peso semelhantes à maturidade.

Todas as variáveis analisadas foram influenciadas pelo nível de alimentação, exceto o rendimento verdadeiro (RV). As médias do PC, PCA e PCV dos animais AV foram, respectivamente, 33,$9 ; 33,7$ e $36,0 \%$ superior às dos cabritos AR, apresentando, conseqüentemente, carcaça 39,9\% mais pesada $(12,10 \mathrm{~kg}$ vs $8,65 \mathrm{~kg}$, respectivamente). Esta diferença deveu-se ao maior consumo de MS dos animais alimentados $\operatorname{AV}(0,65 \mathrm{~kg} / \mathrm{dia})$ em relação aos $\operatorname{AR}(0,41 \mathrm{~kg} / \mathrm{dia})$, pois tiveram maior aporte nutricional e, por conseguinte, melhor desempenho. A partir dos dados da Tabela 2, verifica-se que os pesos da carcaça quente e fria dos animais com alimentação AV tiveram incremento médio de $0,54 \mathrm{~kg}$ e $0,53 \mathrm{~kg}$, respectivamente, para cada quilograma de aumento do PCA.

O aumento no PCA nos cabritos Moxotó e Canindé, de 18,82 para $25,17 \mathrm{~kg}$ incrementou o RCQ de 46,0 para $48,1 \%$ e o RC de 43,6 para 46,1\%. Segundo Lawrence \& Fowler (2002), este resultado pode ser explicado pelo fato de o aumento no peso da carcaça ser superior ao dos demais componentes do peso corporal. Estudos realizados por 
Tabela 2 - Médias de peso corporal final (PC), peso corporal ao abate (PCA), peso do corpo vazio (PCV), peso da carcaça quente (PCQ), peso da carcaça fria (PCF), índice de quebra por resfriamento (IQ), rendimento de carcaça quente (RCQ), rendimento verdadeiro $(\mathrm{RV})$ e rendimento comercial $(\mathrm{RC})$ em função da raça e do nível de alimentação

Table 2 - Means of final body weight (FBW), slaughter body weight (SBW), empty body weight (EBW), hot carcass weight (HCW), cold carcass weight (CCW), cooling loss index (CLI), hot carcass yield (HCY), true carcass yield (TCY), and commercial carcass yield (CCY) according to different breed and feeding level

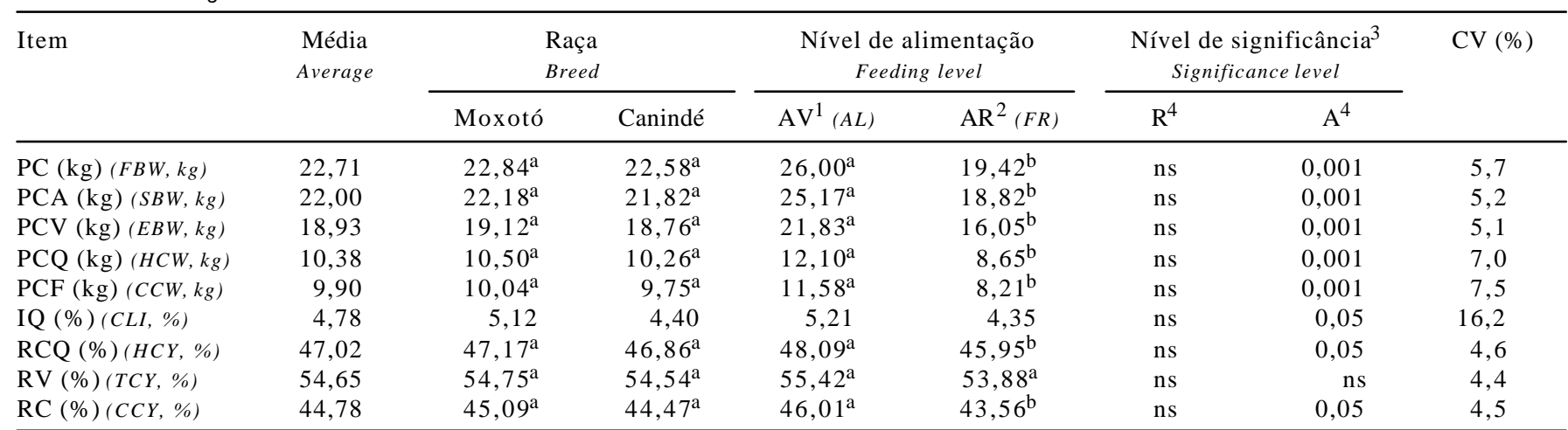

${ }^{1} \mathrm{AV}=$ alimentação à vontade $(A L=$ fed ad libitum); $2 \mathrm{AR}=37 \%$ de restrição $\quad(F R=37 \%$ of feed restriction); 3 ns Não-significativo (not significant); ${ }^{4} \mathrm{R}=$ raça(breed); $\mathrm{A}=$ nível de alimentação (feeding level).

Médias na linha seguidas de letras diferentes diferem $(P<0,001 ; P<0,05)$ pelo teste $F$.

Means followed by different superscripts in the same row differ $(P<0.001 ; P<0.05)$ by $F$ test.

Lloyd et al. (1980), Kemp et al. (1981) e Bueno et al. (1998) demonstraram que maior peso ao abate origina maior peso de carcaça e aumento no rendimento da carcaça. Yáñez (2002) encontrou, respectivamente, para os níveis 0 e $30 \%$ de restrição, 57,2 e $56,2 \%$ de RV e 47,3 e 47,2\% de RC em cabritos Saanen abatidos com $35 \mathrm{~kg}$ de peso corporal (PC). Pereira Filho et al. (2005), trabalhando com cabritos mestiços F1 Boer x Saanen com os mesmos níveis de restrição e abatidos com $25 \mathrm{~kg}$ de PC, encontraram 47,1 e 47,7\% para rendimento de carcaça quente em relação ao PCA, 56,4 e $57,8 \%$ para RV e 45,7 e $46,1 \%$ para RC. Contudo, estes autores não observaram influência do nível de restrição para estas variáveis, o que difere dos resultados obtidos neste trabalho com relação ao RCQ e RC. Os rendimentos de carcaça quente e comercial dos animais com alimentação AV também foram semelhantes aos obtidos por Cunha et al. (2000) em caprinos Saanen (48,6 e 45,8\%) e mestiços Boer (47,8 e 46,3\%, respectivamente) com PCA de $22,6 \mathrm{~kg}$. Foram superiores, no entanto, aos rendimentos encontrados por Figueiredo et al. e Padilha, citados por Costa et al. (1990), para caprinos nativos $(34,5$ e 39,4\%, respectivamente) em condições de manejo tradicional do Nordeste brasileiro e superiores ainda aos rendimentos de carcaça quente e comercial (39,5 e 40,7\%, respectivamente) obtidos por Bellaver et al. (1983), em caprinos de raças nativas com PCA de 19,4 kg.

$\mathrm{O}$ rendimento do animal depende também do desenvolvimento dos componentes não-carcaça e dos fatores que o influenciam (alimentação, duração do jejum, desenvolvimento do trato gastrintestinal, idade) e, conseqüentemente, t em efeito sobre o rendimento da carcaça. Neste trabalho, o efeito da restrição alimentar sobre o PC, o PCA e o PCV não foi suficiente para refletir sobre o RV. A influência da nutrição sobre o rendimento da carcaça está associada, principalmente, a variações no peso do conteúdo do trato gastrintestinal (Warmington \& Kirton, 1990; Kadim et al., 2003) e dos órgãos internos (Warmington $\&$ Kirton, 1990), as quais refletem maior representatividade dos componentes não-carcaça sobre o PCV nos animais alimentados com AR em relação aos AV, resultando em RV similares quando as variações influenciadas pelo CTGI foram eliminadas.

As perdas por jejum $(0,718 \pm 0,524 \mathrm{~kg})$ não foram influenciadas pela raça ou pelo nível de alimentação. Da mesma forma, as perdas por resfriamento $(0,485 \pm 0,164 \mathrm{~kg})$ decorrentes das perdas em umidade da carcaça na câmara fria e as reações químicas ocorridas no músculo durante o resfriamento também não foram influenciadas pelos tratamentos. O índice de quebra por resfriamento (IQ\%), encontrado na Tabela 2 , foi em média $4,78 \%$ e situou-se acima dos valores médios observados em ovinos, próximo aos 3\% (Almeida Jr. et al., 2004). Essa maior porcentagem de perda em relação aos ovinos pode ser atribuída à pouca cobertura de gordura nos caprinos, principalmente os animais nativos, como as raças Moxotó e Canindé.

Como descrito na Tabela 3, a raça não influenciou o peso dos cortes nem seus rendimentos, à semelhança do observado por Barros et al. (1999), ao estudarem o efeito da raça e da alimentação sobre o desempenho de borregos em cruzamento industrial.

As diferenças observadas entre os níveis de alimentação no peso da carcaça fria refletiram nos pesos dos cortes 
Tabela 3 - Médias dos pesos $(\mathrm{kg})$ e rendimentos (\%) dos cortes regionais da carcaça em relação à soma dos pesos das duas meiacarcaças (SMC), em função da raça e do nível de alimentação

Table 3 - Means of weights ( $\mathrm{kg}$ ) and yields (\%) of carcass cuts expressed as percentage of the sum of the left and right half carcass weights (SMC) according to different breed and feeding level

\begin{tabular}{|c|c|c|c|c|c|c|c|c|}
\hline \multirow[t]{2}{*}{ Item } & \multirow[t]{2}{*}{$\begin{array}{l}\text { Média } \\
\text { Average }\end{array}$} & \multicolumn{2}{|c|}{$\begin{array}{l}\text { Raça } \\
\text { Breed }\end{array}$} & \multicolumn{2}{|c|}{$\begin{array}{c}\text { Nível de alimentação } \\
\text { Feeding level }\end{array}$} & \multicolumn{2}{|c|}{$\begin{array}{c}\text { Nível de significância } \\
\text { Significance level }\end{array}$} & \multirow[t]{2}{*}{$\mathrm{CV}(\%)$} \\
\hline & & Moxotó & Canindé & $\mathrm{AV}^{1}(A L)$ & $\mathrm{AR}^{2}(F R)$ & $\mathrm{R}^{4}$ & $A^{4}$ & \\
\hline $\begin{array}{l}\text { Pescoço } \\
\text { Neck }\end{array}$ & 1,27 & $1,33^{\mathrm{a}}$ & $1,21^{\mathrm{a}}$ & $1,47^{\mathrm{a}}$ & $1,07^{b}$ & $\mathrm{~ns}$ & 0,001 & 15,8 \\
\hline $\begin{array}{l}\text { Paletas } \\
\text { Shoulder clods }\end{array}$ & 2,02 & $2,04^{\mathrm{a}}$ & $2,00^{\mathrm{a}}$ & $2,34^{\mathrm{a}}$ & $1,71^{\mathrm{b}}$ & $\mathrm{ns}$ & 0,001 & 7,4 \\
\hline $\begin{array}{l}\text { Costelas }\left(1^{\mathrm{a}}-5^{\mathrm{a}}\right) \\
\text { Ribs, } 1^{s t_{-}} 5^{\text {th }}\end{array}$ & 0,76 & $0,75^{\mathrm{a}}$ & $0,76^{\mathrm{a}}$ & $0,92^{\mathrm{a}}$ & $0,59^{\mathrm{b}}$ & $\mathrm{ns}$ & 0,01 & 27,1 \\
\hline $\begin{array}{l}\text { Costelas }\left(6^{\mathrm{a}}-13^{\mathrm{a}}\right) \\
\text { Ribs, } 6^{\text {th }}-13^{\text {th }}\end{array}$ & 1,09 & $1,13^{\mathrm{a}}$ & $1,05^{\mathrm{a}}$ & $1,30^{\mathrm{a}}$ & $0,88^{b}$ & $\mathrm{~ns}$ & 0,001 & 9,0 \\
\hline $\begin{array}{l}\text { Lombo } \\
\text { Loin }\end{array}$ & 0,97 & $1,00^{\mathrm{a}}$ & $0,95^{\mathrm{a}}$ & $1,16^{\mathrm{a}}$ & $0,79^{\mathrm{b}}$ & $\mathrm{ns}$ & 0,001 & 8,3 \\
\hline $\begin{array}{l}\text { Pernas } \\
\text { Hind legs }\end{array}$ & 2,93 & $2,97^{\mathrm{a}}$ & $2,89^{\mathrm{a}}$ & $3,36^{\mathrm{a}}$ & $2,50^{\mathrm{b}}$ & $\mathrm{ns}$ & 0,001 & 6,9 \\
\hline$\% \mathrm{SMC}$ & & & & & & & & \\
\hline $\begin{array}{l}\text { Pescoço } \\
\text { Neck }\end{array}$ & 12,73 & $13,17^{\mathrm{a}}$ & $12,29^{\mathrm{a}}$ & $12,57^{\mathrm{a}}$ & $12,88^{\mathrm{a}}$ & $\mathrm{ns}$ & $\mathrm{ns}$ & 12,8 \\
\hline $\begin{array}{l}\text { Paletas } \\
\text { Shoulder clods }\end{array}$ & 20,33 & $20,19^{\mathrm{a}}$ & $20,46^{\mathrm{a}}$ & $20,07^{\mathrm{a}}$ & $20,60^{\mathrm{a}}$ & $\mathrm{ns}$ & $\mathrm{ns}$ & 3,4 \\
\hline $\begin{array}{l}\text { Costelas }\left(1^{\mathrm{a}}-5^{\mathrm{a}}\right) \\
\text { Ribs, } 1^{\text {st }}-5^{\text {th }}\end{array}$ & 7,50 & $7,38^{\mathrm{a}}$ & $7,62^{\mathrm{a}}$ & $7,85^{\mathrm{a}}$ & $7,14^{\mathrm{a}}$ & $\mathrm{ns}$ & $\mathrm{ns}$ & 20,3 \\
\hline $\begin{array}{l}\text { Costelas }\left(6^{\mathrm{a}}-13^{\mathrm{a}}\right) \\
\text { Ribs, } 6^{\text {th }}-13^{\text {th }}\end{array}$ & 10,87 & $11,12^{\mathrm{a}}$ & $10,63^{\mathrm{a}}$ & $11,12^{\mathrm{a}}$ & $10,63^{\mathrm{a}}$ & $\mathrm{ns}$ & $\mathrm{ns}$ & 5,1 \\
\hline $\begin{array}{l}\text { Lombo } \\
\text { Loin }\end{array}$ & 9,71 & $9,81^{\mathrm{a}}$ & $9,60^{\mathrm{a}}$ & $9,91^{\mathrm{a}}$ & $9,50^{\mathrm{a}}$ & $\mathrm{ns}$ & $\mathrm{ns}$ & 5,4 \\
\hline $\begin{array}{l}\text { Pernas } \\
\text { Hind legs }\end{array}$ & 29,52 & $29,45^{\mathrm{a}}$ & $29,59^{\mathrm{a}}$ & $28,77^{\mathrm{a}}$ & $30,27^{\mathrm{a}}$ & $\mathrm{ns}$ & 0,01 & 3,5 \\
\hline
\end{tabular}

$1 \mathrm{AV}=$ alimentação à vontade $\left(A L=\right.$ fed ad libitum); ${ }^{2} \mathrm{AR}=37 \%$ de restrição $(F R=37 \%$ of feed restriction); 3 ns Não-significativo (not significant);

${ }^{4} \mathrm{R}=$ raça(breed); $\mathrm{A}=$ nível de alimentação (feeding level).

Médias na linha seguidas de letras diferentes diferem $(P<0,001 ; P<0,05)$ pelo teste $F$.

Means followed by different superscripts in the same row differ $(P<0.001 ; P<0.05)$ by $F$ test.

quando expressos em valores absolutos. Os pesos médios de pescoço, paletas, costelas $1^{\mathrm{a}}-5^{\mathrm{a}}$, costelas $6^{\mathrm{a}}-13^{\mathrm{a}}$, lombo, pernas e baixos dos animais com alimentação AV foram, respectivamente, 40,$2 ; 36,8 ; 55,9 ; 47,7 ; 34,4$ e $49,3 \%$ superior ao dos animais com AR.

Apesar da resposta positiva do nível de alimentação sobre os cortes comerciais da carcaça, torna-se necessária a avaliação em termos percentuais, para verificar a importância de cada corte em relação ao peso da carcaça fria. À exceção da influência da alimentação sobre o rendimento da perna, os demais rendimentos foram semelhantes. Os resultados obtidos considerando-se a semelhança entre as raças, quanto às porcentagens dos cortes, reforçam a lei da harmonia anatômica (Boccard \& Dumont, citados por Siqueira et al., 2001) de que, em carcaças com pesos e quantidades de gordura similares, quase todas as regiões corporais se encontram em proporções semelhantes, independentemente da conformação dos genótipos considerados.

O menor rendimento de perna em animais alimentados AV justifica-se pelo fato de o seu desenvolvimento ser precoce, podendo sofrer reduções nas suas proporções em relação à carcaça com o aumento do peso corporal. Esses resultados estão de acordo com Colomer-Rocher et al. (1992) e Furusho-Garcia et al. (2004), que observaram, respectivamente, em cabritos Saanen e cordeiros mestiços Santa Inês, diminuições na porcentagem da perna com o aumento do peso do animal.

Osório et al. (1995b) relataram que os membros apresentam desenvolvimento precoce, o que ocasiona redução nas porcentagens desses cortes quando ocorre aumento no peso da carcaça. Diferentemente dos resultados obtidos 
neste trabalho, Colomer-Rocher et al. (1992) verificaram que a proporção da paleta diminuiu com o aumento do peso da carcaça, enquanto Pereira Filho (2003) verificou que a proporção da paleta e do pescoço regrediu linearmente em relação ao peso da carcaça fria, obtido pela recomposição dos pesos dos cortes comerciais. Yáñez (2002) encontrou reduções nas proporções das costelas $\left(6^{a}-13^{a}\right)$ e aumento nas de paleta e pescoço com o aumento da restrição alimentar; todavia, as proporções das pernas, costelas $\left(1^{\mathrm{a}}-5^{\mathrm{a}}\right) \mathrm{e}$ baixos mantiveram-se constantes.

O rendimento das costelas, região onde a gordura se acumula em maior velocidade, aumentando sua proporção na carcaça à medida que o peso do animal aumenta (crescimento tardio), não foi influenciado pela alimentação. Pode-se inferir, portanto, que os animais ainda não haviam alcançado seu crescimento máximo no momento do abate, apesar de as costelas apresentarem superioridade de $6,8 \%$ nos animais com alimentação $\mathrm{AV}$ em relação àqueles com AR, fato confirmado pela semelhança entre os rendimentos do pescoço e pela característica sexual secundária, comumente observada em ruminantes à medida que o peso corporal do animal aumenta (Colomer-Rocher et al., 1992).

A participação dos cortes na carcaça permite uma avaliação qualitativa, pois deve apresentar a melhor proporção possível de cortes com maior conteúdo de tecidos comestíveis, principalmente músculos (Yáñez, 2002), ou ainda, a melhor proporção possível de cortes de interesse ao consumidor.

A soma da porcentagem dos cortes de maior valor comercial (perna, paleta e lombo) não foi influenciada pelos níveis de alimentação, representando 58,8\% da soma das meia-carcaças nos animais com alimentação AV, valores menores que os observados por Yáñez (2002) e Yamamoto et al. (2000), em cabritos Saanen abatidos com 25 e $27 \mathrm{~kg}$ de peso corporal, respectivamente, resultado que pode ser justificado pelo maior tamanho dos cabritos Saanen em relação aos Moxotó e Canindé. Os rendimentos de pescoço, paleta, costelas $\left(1^{\mathrm{a}}-5^{\mathrm{a}}\right)$, costelas $\left(6^{\mathrm{a}}-13^{\mathrm{a}}\right)$, lombo, perna e baixo observados por Yáñez (2002) foram 10,0; 23,0; 6,4; 9,$4 ; 10,0 ; 32,1$ e $9,1 \%$, respectivamente, para os animais sem restrição alimentar. No Nordeste, as costelas são muito valorizadas pelo mercado consumidor, alcançando valores semelhantes ao quilograma da perna. A soma da porcentagem destes dois cortes assume valores semelhantes, 47,7 e 48,0\%, respectivamente, para os níveis de alimentação AV e AR.

Os resultados observados sugerem, de modo geral, que os cortes de maior valor comercial mantêm sua participação na carcaça, representando 48,8 a 50,9\% quando se consideram paleta e perna, 58,8 a $60,4 \%$ quando incorporada a porcentagem do lombo e, finalmente, 77,7 a 78,1\% quando se consideram paleta, costelas $\left(1^{\mathrm{a}}-13^{\mathrm{a}}\right)$, lombo e perna, respectivamente, para os níveis de alimentação AV e AR. Os valores confirmam a qualidade das carcaças de cabritos Moxotó e Canindé terminados em confinamento.

A influência da raça sobre os componentes do peso corporal (Tabela 4) encontra-se relacionada à maturidade entre elas (Costa et al., 1999; Osório et al., 1995a). Considerando que as raças Moxotó e Canindé apresentam peso e tamanho à maturidade semelhantes, não foi observada influência da raça sobre o peso e rendimento dos NCC.

O incremento no PCA refletiu no peso dos NCC. Segundo Jenkins \& Leymaster (1993), órgãos essenciais aos processos vitais de respiração e metabolismo possuem desenvolvimento maior ao nascimento, enquanto aqueles associados à locomoção e ao armazenamento de nutrientes apresentam desenvolvimento mais tardio. A influência do nível de alimentação sobre o peso de órgãos de crescimento precoce como coração, fígado, pulmão e rins resultou do maior nível de consumo de alimento dos animais alimentados $\mathrm{AV}$, ocasionando maior desenvolvimento pelo maior aporte de nutrientes e pelo possível incremento na taxa metabólica.

O aumento da gordura total não-carcaça (GTNC) está de acordo com os resultados obtidos por Bueno et al. (2000), que relataram que, à medida que as idades e, conseqüentemente, os pesos de abate de cordeiros Suffolk aumentaram, as quantidades de gordura mesentérica e pélvica-renal também aumentaram. Além disso, caprinos apresentam tendência em depositar mais gordura nãocarcaça e menos gordura na carcaça, ou seja, gordura subcutânea, inter e intramuscular (Gaili \& Ali, 1985; Colomer-Rocher et al., 1992). Raças de menor tamanho, como Moxotó e Canindé, devem ser abatidas, a pesos menores que raças de maior tamanho, a fim de evitar a necessidade de retirada da gordura em excesso, o que desvaloriza o produto no mercado consumidor.

A quantidade de alimento ingerida durante o período experimental foi responsável pelo maior desenvolvimento (kg) do trato gastrintestinal vazio (TGIvz). No entanto, as diferenças em peso não foram mantidas quando expresso em relação ao PCV, ou seja, apesar do TGIvz apresentar maior peso nos animais com AV, sua proporção em relação ao PCV foi menor que nos animais com AR. Por sua vez, as diferenças no peso, observadas para conteúdo do trato gastrintestinal (CTGI), contribuíram para o aumento no rendimento de carcaça quente com o aumento de 46,0 para $48,1 \%$ no PCA, respectivamente, para os níveis de alimentação AR e AV, demonstrando que o TGI representa uma variável determinante do rendimento de carcaça. Portanto, quando o objetivo é expressar adequadamente o desempe- 
Tabela 4 - Média dos pesos (kg) e dos rendimentos dos componentes não-carcaça (\%NCC), em função da raça e do nível de alimentação Table 4 - Means of non-carcass component weights (\%NCW) according to different breed and feeding level

\begin{tabular}{|c|c|c|c|c|c|c|c|c|}
\hline \multirow[t]{2}{*}{ Item } & \multirow[t]{2}{*}{$\begin{array}{l}\text { Média } \\
\text { Average }\end{array}$} & \multicolumn{2}{|c|}{$\begin{array}{l}\text { Raça } \\
\text { Breed }\end{array}$} & \multicolumn{2}{|c|}{$\begin{array}{c}\text { Nível de alimentação } \\
\text { Feeding level }\end{array}$} & \multicolumn{2}{|c|}{$\begin{array}{l}\text { Nível de significância } \\
\text { Significance level }\end{array}$} & \multirow[t]{2}{*}{$\mathrm{CV}(\%)$} \\
\hline & & Moxotó & Canindé & $\operatorname{AV}^{1}(A L)$ & $\mathrm{AR}^{2}(F R)$ & $\mathrm{R}^{4}$ & $\mathrm{~A}^{4}$ & \\
\hline \multicolumn{9}{|l|}{$\mathrm{kg}$} \\
\hline Coração (Heart) & 0,10 & $0,09^{\mathrm{a}}$ & $0,10^{\mathrm{a}}$ & $0,12^{\mathrm{a}}$ & $0,07^{b}$ & $\mathrm{~ns}$ & 0,01 & 27,7 \\
\hline Fígado (Liver) & 0,33 & $0,35^{\mathrm{a}}$ & $0,32^{\mathrm{a}}$ & $0,40^{\mathrm{a}}$ & $0,27^{\mathrm{b}}$ & $\mathrm{ns}$ & 0,001 & 9,3 \\
\hline Pulmão(Lungs) & 0,16 & $0,16^{\mathrm{a}}$ & $0,16^{\mathrm{a}}$ & $0,18^{\mathrm{a}}$ & $0,13^{b}$ & $\mathrm{~ns}$ & 0,001 & 11,1 \\
\hline Pele(Skin) & 1,48 & $1,46^{\mathrm{a}}$ & $1,49^{\mathrm{a}}$ & $1,68^{\mathrm{a}}$ & $1,28^{\mathrm{b}}$ & $\mathrm{ns}$ & 0,001 & 13,4 \\
\hline Sangue (Blood) & 0,80 & $0,87^{\mathrm{a}}$ & $0,75^{\mathrm{a}}$ & $0,92^{\mathrm{a}}$ & $0,70^{\mathrm{b}}$ & $\mathrm{ns}$ & 0,05 & 14,4 \\
\hline Cabeça (Head) & 1,57 & $1,58^{\mathrm{a}}$ & $1,56^{\mathrm{a}}$ & $1,69^{\mathrm{a}}$ & $1,45^{b}$ & $\mathrm{~ns}$ & 0,001 & 7,4 \\
\hline GTNC $^{5}$ & 1,32 & $1,33^{\mathrm{a}}$ & $1,31^{\mathrm{a}}$ & $1,64^{\mathrm{a}}$ & $1,00^{\mathrm{b}}$ & $\mathrm{ns}$ & 0,001 & 26,8 \\
\hline TGIvz 6 & 1,01 & $0,99^{\mathrm{a}}$ & $1,02^{\mathrm{a}}$ & $1,09^{\mathrm{a}}$ & $0,91^{b}$ & $\mathrm{~ns}$ & 0,01 & 13,4 \\
\hline $\mathrm{CTGI}^{7}$ & 3,05 & $3,06^{\mathrm{a}}$ & $3,05^{\mathrm{a}}$ & $3,34^{\mathrm{a}}$ & $2,77^{b}$ & $\mathrm{~ns}$ & 0,05 & 18,0 \\
\hline Pulmão (Lungs) & 0,84 & $0,84^{\mathrm{a}}$ & $0,84^{\mathrm{a}}$ & $0,84^{\mathrm{a}}$ & $0,83^{\mathrm{a}}$ & $\mathrm{ns}$ & $\mathrm{ns}$ & 10,6 \\
\hline Rins (Kidney) & 0,30 & $0,29^{\mathrm{a}}$ & $0,31^{\mathrm{a}}$ & $0,29^{\mathrm{a}}$ & $0,30^{\mathrm{a}}$ & $\mathrm{ns}$ & ns & 10,2 \\
\hline Língua (Tongue) & 0,38 & $0,37^{\mathrm{a}}$ & $0,39^{\mathrm{a}}$ & $0,38^{\mathrm{a}}$ & $0,39^{\mathrm{a}}$ & $\mathrm{ns}$ & ns & 14,8 \\
\hline Pele(Skin) & 7,80 & $7,63^{\mathrm{a}}$ & $7,97^{\mathrm{a}}$ & $7,68^{\mathrm{a}}$ & $7,92^{\mathrm{a}}$ & $\mathrm{ns}$ & ns & 10,2 \\
\hline Sangue (Blood) & 4,29 & $4,56^{\mathrm{a}}$ & $4,02^{\mathrm{a}}$ & $4,21^{\mathrm{a}}$ & $4,37^{\mathrm{a}}$ & $\mathrm{ns}$ & $\mathrm{ns}$ & 14,0 \\
\hline Cabeça (Head) & 8,40 & $8,37^{\mathrm{a}}$ & $8,42^{\mathrm{a}}$ & $7,74^{b}$ & $9,05^{\mathrm{a}}$ & $\mathrm{ns}$ & 0,001 & 7,1 \\
\hline GTNC $^{5}$ & 6,87 & $6,94^{\mathrm{a}}$ & $6,80^{\mathrm{a}}$ & $7,53^{\mathrm{a}}$ & $6,21^{\mathrm{a}}$ & $\mathrm{ns}$ & $\mathrm{ns}$ & 25,3 \\
\hline TGIvz 6 & 5,36 & $5,23^{\mathrm{a}}$ & $5,49^{\mathrm{a}}$ & $5,01^{\mathrm{b}}$ & $5,71^{\mathrm{a}}$ & $\mathrm{ns}$ & 0,05 & 14,0 \\
\hline
\end{tabular}

$1 \mathrm{AV}=$ alimentação à vontade $\left(A L=\right.$ fed ad libitum); ${ }^{2} \mathrm{AR}=37 \%$ de restrição $\quad(F R=37 \%$ of feed restriction); 3 ns Não-significativo (not significant); ${ }^{4} \mathrm{R}=$ raça (breed); $\mathrm{A}=$ nível de alimentação(feedinglevel); ${ }^{5}$ Gordura total não-carcaça = gordura omental, gordura mesentérica, gordura interna e gordura pélvicarenal (Total non-carcass fat =omental fat, mesentric fat, internal fat and pelvic-kidney fat); ${ }^{6}$ Trato gastrintestinal vazio (empty gut); ${ }^{7}$ Conteúdo do trato gastrintestinal (digestive contents).

a,b Médias na linha seguidas de letras diferentes diferem pelo teste $F(P<0,001 ; P<0,01$ e $P<0,05)$.

$a, b$ Means followed by different superscripts in the same row differ $(P<0.001, P<0.01$, and $P<0.05)$ by $F$ test.

nho animal em função dos rendimentos de carcaça e dos componentes não-carcaça, deve-se utilizar o PCV, e não o PCA, por não considerar o CTGI.

Da mesma forma que os demais NCC, o maior peso para a pele dos animais alimentados AV decorre do maior desenvolvimento, estimulado pelo maior consumo de alimentos, quando comparados aos animais com alimentação restrita. Os valores médios, em kg, obtidos neste trabalho com os animais com alimentação AV, para coração e TGIvz foram maiores que os obtidos por Tonetto et al. (2004), em cordeiros confinados e abatidos aos $31 \mathrm{~kg}$; para pele, sangue, pulmão, coração e fígado, contudo, foram menores. Comparando aos resultados obtidos por Silva Sobrinho et al. (2003), os valores observados foram semelhantes para língua e menores para coração, pulmões, fígado e rins, em cordeiros abatidos aos 30 e $34 \mathrm{~kg}$.

Observa-se na Tabela 4 que, apesar do aumento em peso dos NCC com o nível de alimentação AV, esta tendência não foi observada na maioria dos componentes quando expressos como porcentagem do PCV. Apenas o fígado aumentou seu rendimento com o incremento do PCA nos animais com alimentação AV (10,9\%, em relação aos animais com AR), enquanto a cabeça e o trato gastrintestinal vazio (TGIvz) aumentaram em proporção com a restrição alimentar. Lawrence \& Fowler (2002) comentam que a restrição alimentar causa mobilização dos nutrientes dos tecidos na ordem inversa da sua maturidade, ou seja, gordura, músculo, ossos, cérebro e sistema nervoso central. A restrição alimentar promoveu redução na taxa de crescimento da carcaça, levando a incrementos dos componentes nãocarcaça em relação ao PCV.

A diferença observada no rendimento do fígado entre os níveis de alimentação foi ocasionada pela maior taxa metabólica promovida pelo maior consumo de MS. Tendo em vista o maior desenvolvimento em peso, proporcionalmente, verificou-se maior participação do órgão no PCV. Este resultado diverge do obtido por Rosa et al. (2002), que não encontraram diferença significativa nos percentuais de órgãos de crescimento precoce, como coração e fígado.

Os rendimentos (Tabela 4) foram semelhantes para coração, fígado, pele e cabeça, inferiores para rins e superiores para GTNC, em relação aos relatados por Dandha et 
al. (2003) para caprinos abatidos com 30 a $35 \mathrm{~kg}$ objetivando a produção de carcaças tipo Chevon (16-22 kg).

Costa et al. (1999) afirmaram que, depois da carcaça, a pele e o trato gastrintestinal (TGI) são os componentes de maior importância relativa, corroborando com os resultados obtidos neste trabalho, que totalizaram $12,7 \%$ do PCV.

Em uma mesma espécie, cada raça apresenta um modelo de desenvolvimento ou velocidade de formação dos componentes do corpo e da carcaça (Lawrence \& Fowler, 2002). O diferencial de desenvolvimento dos principais cortes da carcaça apresenta importância antagônica em dois segmentos da cadeia produtiva. Quando o produtor visa alcançar pesos maiores e, conseqüentemente, maiores rendimentos de carcaça, o mercado está adquirindo animais que apresentam, proporcionalmente, menores valores de cortes nobres na carcaça. O peso corporal ao abate de mercado deve ser determinado para cada raça objetivando estimar o ótimo zootécnico (produção $\times$ economia) para ambos os setores.

Embora a seleção natural ao longo dos anos tenha ocorrido de forma negativa na produção de raças nativas no Nordeste, com redução da capacidade produtiva dos rebanhos (carne e leite), pode-se afirmar, com base nos resultados obtidos, que o Nordeste possui hoje, para suas condições de semi-árido, material genético de qualidade para produção de pele e carne de baixo teor de gordura, desde que um nível mínimo de tecnologia seja adotado.

\section{Conclusões}

A raça não determinou diferenças nas características de carcaça e nos componentes não-carcaça, assim como no rendimento dos cortes, quando o peso e o tamanho à maturidade foram semelhantes.

A restrição alimentar afetou o desenvolvimento e a deposição dos tecidos dos animais, resultando em menores rendimentos e quilos de carcaça fria para comercialização.

Cabritos Moxotó e Canindé produziram carcaças com boas características e melhor rendimento de cortes nobres, como perna, quando abatidos com peso corporal inferior a $25 \mathrm{~kg}$.

\section{Agradecimento}

À Universidade Federal Rural de Pernambuco - UFRPE, ao Programa de Pós-Graduação em Zootecnia, do Departa mento de Zootecnia, à CAPES e ao CNPq,pelo apoio para a realização deste trabalho. Aos funcionários do Laboratório de Nutrição Animal - UFRPE, pelo valioso suporte.

\section{Literatura Citada}

ACHE TUDO E REGIÃO. Localização e dados gerais Recife PE. Disponível em: <http://www.achetudoeregiao.com.br/PE/ recife_localizacao.htm>. Acesso em: 09/12/2004.

ALMEIDA JR., G.A.; COSTA, C.; MONTEIRO, A.L.G. et al. Desempenho, características de carcaça e resultado econômico de cordeiros criados em creep feeding com silagens de grãos úmidos de milho. Revista Brasileira de Zootecnia, v.33, n.4, p.1048-1059, 2004

ANOUS, M.R.; MOURAD, M. Some carcass characteristics of Alpine kids under intensive versus semi-intensive systems of production in France. Small Ruminant Research, v.40, p.193-196, 2001.

ASSOCIAÇÃO BRASILEIRA DE CRIADORES DE CAPRINOS $A B C C$. Regulamento do serviço de registro genealógico das raças caprinas. Recife: $A B C C, 2000.16 p$.

ATTI, N.; ROUISSI, H.; MAHOUACHI, M. The effect of dietary crude protein level on growth, carcass and meat composition of male goat kids in Tunisia. Small Ruminant Research, v.54, p.89-97. 2004.

BARROS, N.N.; FIGUEIREDO, E.A.P.; BARBIERI, M.E. Efeito do genótipo e da alimentação no desempenho de borregos de cruzamento industrial em confinamento. Revista Científica de Produção Animal, n.4, p.59-67, 1999.

BELLAVER, C.; FIGUEIREDO, E.A.P.; OLIVEIRA, E.R. et al. Carcass characteristics of goats and sheep in Northeast Brazil. Pesquisa Agropecuária Brasileira, v.18, n.3, p.301-309, 1983.

BUENO, M.S.; CUNHA, E.A.; SANTOS, L.E. et al. Características de carcaça de cordeiros Suffolk abatidos em diferentes idades. Revista Brasileira de Zootecnia, v.29, n.6, p.1803-1810, 2000.

BUENO, M.S.; CUNHA, E.M; SANTOS, L.E. et al. Avaliação de carcaças de cordeiros Suffolk abatidos com diferentes pesos vivos. In: REUNIÃO ANUAL DA SOCIEDADE BRASILEIRA DE ZOOTECNIA, 35., 1998, Botucatu. Anais... Botucatu: Sociedade Brasileira de Zootecnia, 1998. v.4, p.573-575.

BUENO, M.S.; SANTOS, L.E.; CUNHA, E.A. et al. Avaliação de carcaças de cabritos abatidos com diferentes pesos vivos. Revista Nacional da Carne, n.273, p.72-79, 1999.

COLOMER-ROCHER, F. Factors influencing carcass quality. Carcass component and composition. In: INTERNATIONAL CONFERENCE ON GOATS, 4., 1987, Brasília.Proceedings... Brasília: EMBRAPA, 1987. p.181-194.

COLOMER-ROCHER, F.; KIRTON, A.H.; MERCER, G.J.K. et al. Carcass composition of New Zealand Saanen goats slaughtered at different weights. Small Ruminant Research, v.7, p.161173,1992

COLOMER-ROCHER, F.; MORAND-FEHR, P.; KIRTON, A.H. et al. Métodos normatizados para el estudio de los caracteres cuantitativos y cualitativos de las canales caprinas y ovinas. Madrid: Ministerio da Agricultura, Pesca y Alimentación. 1988. p.41. (Instituto Nacional de Investigaciones Agrárias, Cuadernos 17)

COSTA, J.C.C.; OSÓRIO, J.C.S; SILVA, C.A.S. et al. Componente do peso vivo em cordeiros não castrados. Revista Brasileira de Agrociência, v.5, n.1, p.42-44, 1999.

COSTA, R.G.; PIMENTA FILHO, E.C.; MOREIRA, R.T. et al. Rendimento de carcaça e vísceras em caprinos mestiços AngloNubianos. Agropecuária Técnica, v.11, n.1/2, p.3-8, 1990.

CUNHA, E.; BUENO, M.S.; RODRIGUES, C.F. et al. Desempenho e características de carcaças de cabritos Saanen e mestiços Boer. In: REUNIÃO ANUAL DA SOCIEDADE BRASILEIRA DE ZOOTECNIA, 40., 2000, Viçosa, MG. Anais... Viçosa, MG: Sociedade Brasileira de Zootecnia (CD-ROM).

DHANDA, J.S.; TAYLOR, D.G.; MURRAY, P.J. Part 1. Growth, carcass and meat quality parameters of male goats: effects of genotype and liveweight at slaughter. Small Ruminant Research, v.50, p.57-66, 2003. 
EL KHIDIR, I.A.; BABIKER, S.A.; SHAFIE, S.A. Comparative feedlot performance and carcass characteristics of Sudanese desert sheep and goat. Small Ruminant Research, v.30, p.147-151, 1998

FURUSHO-GARCIA, I.R.; PEREZ, J.R.O.; BONAGURIO, S. et al. Estudo dos cortes da carcaça de cordeiros Santa Inês puros e cruzas Santa Inês com Texel, Ile de France e Bergamácia. Revista Brasileira de Zootecnia, v.33, n.2, p.453-462, 2004.

GAILI, E.S.; ALI, A.E. Meat from Sudan desert sheep and goats. Part 1: Carcass yield, offals and distribution of carcass tissues. Meat Science, v.13, p.217-227, 1985.

GARCIA, C.A.; MONTEIRO, A.L.G.; COSTA, C. et al. Medidas objetivas e composição tecidual da carcaça de cordeiros alimentados com diferentes níveis de energia em creep feeding. Revista Brasileira de Zootecnia, v.32, n.6, p.1380-1390, 2003.

INSTITUTO DO MILÊNIO. Caracterização das áreas de estudo geologia e oceanografia PE. Disponível em: <http://200.17.232.197/milenio/MMEOC1/GeolOcPE.htm>. Acesso em: 12/01/05.

JENKINS, T.G.; LEYMASTER, K.A. Estimates of maturing rates and masses at maturity for body components of sheep.Journal of Animal Science, v.71, p.2952-2957, 1993.

KADIM, I.T.; MAHGOUB, O.;AL-AJMI, D.S. et al. An evaluation of the growth, carcass and meat quality characteristics of Omani goat breeds. Meat Science, v.66, p.203-210, 2003.

KEMP, J.D.; MAHYUDDIN, M.; ELY, D.G. et al. Effect of feeding systems, slaughter and sex on organoleptic properties, and fatty acid composition on lamb. Journal of Animal Science, v.51, n.2, p.321, 1981

LAWRENCE, T.L.J.; FOWLER, V.R. Growth of farm animals. 2.ed. Wallingford: CAB International, 2002. 346p.

LLOYD, W.R.; SLYTER, A.L.; COSTELLO, W.J. Effect of breed, sex and final weight on feedlot performance, carcass characteristic and meat palatability of lambs. Journal of Animal Science, v.51, n.2, p.316-320, 1980.

McCLELLAND, T.H.; BONAITI, B.; TAYLOR, St.C.S. Breed differences in body composition of equaly mature sheep. Animal Production, v.23, p.125-129, 1976.

MENDONÇA, G.; OSÓRIO, J.C.; OLIVEIRA, N.M. et al. Morfologia, características da carcaça e componentes do peso vivo em borregos Corriedale e Ideal. Ciência Rural, v.33, n.2, 2003.

MORON-FUENMAYOR, O.E.; CLAVERO, T. The effect of feeding system on carcass characteristics, non-carcass components and retail cut percentages of lambs. Small Ruminant Research, v.34, p.57-64, 1999.

MTENGA, L.A.; KITALY, A.J. Growth performance and carcass characteristics of tanzanian goats fed Chloris gayana hay with different levels of protein supplement. Small Ruminant Research, v.3, p.1-8, 1990.

NATIONAL RESEARCH COUNCIL - NRC. Nutrient requirements of dairy cattle. 7.rev.ed. Washington, D.C.: National Academy Press, 2001. 356p.

OSÓRIO, J.C.S.; SIERRA, I.; SAÑUDO, C. Componentes do peso vivo em cordeiros e borregos Polwarth e cruzas Texel x Polwarth. Ciência Rural, v.25, n.1, p.1349-143, 1995a.

OSÓRIO, J.C.S.; SIEWERDT, F.; OSÓRIO, M.T.M. et al. Desenvolvimento alométrico das regiões corporais em ovinos. Revista Brasileira de Zootecnia, v.24, n.2, p.326-333, 1995 b.

PEREIRA FILHO, J.M.; RESENDE, K.T.; TEIXEIRA, I.A.M.A. et al. Efeito da restrição alimentar no desempenho produtivo e econômico de cabritos F1 Boer x Saanen. Revista Brasileira de Zootecnia, v.34, n.1, p.188-196, 2005.
ROSA, G.T.; PIRES, C.C.; SILVA, J.H.S. et al. Proporções e coeficientes de crescimento dos não-componentes da carcaça de cordeiros e cordeiras em diferentes métodos de alimentação. Revista Brasileira de Zootecnia, v.31, n.6, p.2290-2298, 2002.

SAHLU, T.; HART, S.P.; GOETSCH, A.L. Effects of level of feed intake on body weight, body components, and mohair growth in Angora goats during realimentation. Small Ruminant Research, v.32, p.251-259, 1999.

SEN, A.R.; SANTRA, A.; KARIM, S.A. Carcass yield, composition and meat quality attributes of sheep and goat under semiarid conditions. Meat Science, v.66, p.757-763, 2004.

SILVA SOBRINHO, A.G.; GAST ALDI, K.A.; GARCIA, C.A. et al. Diferentes dietas e pesos ao abate na produção de órgãos de cordeiros. Revista Brasileira de Zootecnia, v.32, n.6, p.17921799, 2003 (Supl. 1).

SILVA SOBRINHO, A.G.; GONZAGA NETO, S. Produção de carne caprina e cortes da carcaça. Disponível em: <http://www.capritec.com.br/pdf/producao_carnecaprina.PDF > Acesso em: 28/03/04.

SIQUEIRA E.R.; SIMÕES, C.D.; FERNANDES, S.Efeito do sexo e do peso ao abate sobre a produção de carne de cordeiro. Morfometria da carcaça, pesos dos cortes, composição tecidual e componentes não constituintes da carcaça. Revista Brasileira de Zootecnia, v.30, n.4, p.1299-1307, 2001.

TONETTO, C.J.; PIRES, C.C.; MÜLLER, L. et al. Rendimento dos cortes de carcaça, características da carne e componentes do peso vivo em cordeiros terminados em três sistemas de alimentação. Revista Brasileira de Zootecnia, v.33, n.1, p.234-241, 2004.

UNIVERSIDADE FEDERAL DE VIÇOSA - UFV. SAEG - Sistema de análise estatística e genética. Versão 8.0. Viçosa-MG (manual do usuário), 1998. 150p.

VALADARES FILHO, S.C.; ROCHA JR., V.R.; CAPPELLE, E.R. Tabelas de composição de alimentos para bovinos. 1.ed. Viçosa, MG: Universidade Federal de Viçosa, 2002. 297p.

WARMINGTON, B.G.; KIRTON, A.H. Genetic and non-genetic influences on growth and carcass traits of goats. Small Ruminant Research, v.3, p.147-165, 1990.

YAMAMOTO, S.M.; MACEDO, F.A.F.; ALCADE, C.R. et al. Características de carcaça de caprinos jovens, terminados com proteína by pass. In: REUNIÃO ANUAL DA SOCIEDADE BRASILEIRA DE ZOOTECNIA, 37., 2000, Viçosa, MG. Anais... Viçosa, MG: Sociedade Brasileira de Zootecnia, 2000. p.356.

YÁÑEZ, E.A. Desenvolvimento relativo dos tecidos e características da carcaça de cabritos saanen, com diferentes pesos e níveis nutricionais. Jaboticabal: Universidade Estadual Paulista, 2002. 85p. Tese (Doutorado em Zootecnia) - Universidade Estadual Paulista, 2002.

ZUNDT, M.; MACEDO, F.A.F.; ALCADE, C.R. et al. Características de carcaça de caprinos alimentados com diferentes níveis energéticos. In: REUNIÃO ANUAL DA SOCIEDADE BRASILEIRA DE ZOOTECNIA, 38., 2001, Piracicaba. Anais... Piracicaba: Sociedade Brasileira de Zootecnia, 2001. p.992.
Recebido: 08/03/05 Aprovado: 31/05/06 
